\title{
DESEMPENHO DE COLHEDORAS DE PARCELAS NA SOJA COM DIFERENTES VELOCIDADES DE DESLOCAMENTO
}

\author{
PERFORMANCE OF PLOT HARVESTER ON SOYBEANS WITH DIFFERENT \\ DISPLACEMENT DIFFERENT SPEED \&
}

RENDIMIENTO DE LAS COSECHADORAS DE PARCELAS DE SOJA CON DIFERENTE VELOCIDAD DE DESPLAZAMIENTO ${ }^{\circ}$

Recebido em: 09/03/2021 - Aprovado em: 11/08/2021 - Publicado em: 31/08/2021

doi) http://dx.doi.org/10.18011/bioeng2021v15n2p207-219

Matheus Danieli' (matheusdanimaider@gmail.com)

Allan Remor Lopes' (allanremorlopes@gmail.com)

Marcelo Dotto' (marcelo.dotto@unisep.edu.br)

Elouize Xavier ${ }^{1}$ (elo231@hotmail.com)

André Bressiani Machado1 (admachado94@yahoo.com.br)

Vinicius Eduardo Schiavini¹ (schiavinee@hotmail.com)

Camila Moreno Giarola² (camila.giarola@edu.unipar.br)

Kelli Pirola ${ }^{3}$ (kelli_pirola1@hotmail.com)

\footnotetext{
${ }^{1}$ Centro Universitário UNISEP. Dois Vizinhos, Paraná, Brasil.

2 Universidade Paranaense. Umuarama, Paraná, Brasil.

3 Universidade Tecnológica Federal do Paraná. Pato Branco, Paraná, Brasil.
}

\section{RESUMO}

A colheita mecanizada de soja é fundamental no processo produtivo desta cultura e, caso não seja realizada adequadamente, poderá resultar em danos mecânicos severos aos grãos, acarretando prejuízos significativos na colheita. Essa preocupação com a colheita também deve ser levada em consideração em campos experimentais, quando são utilizadas colhedoras de parcelas. Objetivou-se neste trabalho avaliar as perdas ocorridas na colheita mecanizada com uma colhedora de parcelas com diferentes velocidades de deslocamento. Avaliaram-se as perdas na plataforma, na trilha, totais. Além disso, foi avaliada a impureza, o número de vagens e a umidade dos grãos, com as velocidades de deslocamento de: 2, 4, 6 e $8 \mathrm{~km} \mathrm{~h}-1$. O aumento da velocidade de deslocamento proporcionou menores perdas na colheita mecanizada. O número de vagens, as impurezas e a umidade também foram influenciadas pelo aumento da velocidade de deslocamento.

Palavras-chave: Glycine max (L.) Merrill. Colheita mecanizada. Perdas na colheita. 


\section{INTRODUÇÃO}

O Brasil destaca-se no cenário mundial como o maior produtor de soja (Glycine max. (L.) Merril), com crescente evolução e atingindo na safra de 2019/2020 a produção recorde de 124 milhões de toneladas (CONAB, 2020), sendo esse aumento de produção explicado principalmente pelo uso de tecnologias (FREITAS \& MENDONÇA, 2016).

Todas as tecnologias utilizadas na produção de soja, como a mecanização, irrigação, o melhoramento genético, uso de insumos, agrotóxicos, dentre outros, devem ser testados preliminarmente, antes de serem comercializados.

Os testes preliminares são realizados em campos experimentais, que são pequenas áreas destinadas a estudos científicos agrícolas. Para que essas áreas experimentais possam ser manejadas de maneira mais intensiva, produzindo com maior qualidade e precisão, é importante um planejamento adequado, utilizando tecnologias de forma correta, para que os experimentos sejam menores e mais eficientes. Além disso, a ampliação das áreas experimentais não tem sido uma constante nos centros de pesquisa (MARTIN et al., 2007).

Na cultura da soja, a colheita constitui uma importante etapa, principalmente pelos riscos de perdas a que está sujeita a lavoura (GURGACZ et al., 2019). Nesse sentido, para campos experimentais são recomendadas se possível o uso de colhedoras de parcelas, principalmente devido a relação custo-benefício que proporcionam.

Apesar de serem as mais indicadas ao uso experimental, as colhedoras de parcelas assim como as colhedoras convencionais de grãos também apresentam perdas na colheita. Dentre os fatores que podem influenciar nas perdas da colheita mecanizada da soja, podem-se citar altura de corte da plataforma, velocidade do molinete, rotação do cilindro do trilhador, umidade do grão e a velocidade de deslocamento. Para Fernandes et al. (2018) a velocidade com que a colhedora de desloca é um fator preponderante para o adequado funcionamento dos componentes da máquina evitando um percentual de perda de grãos acima do nível satisfatório. Para Zandonadi, Ruffato e Figueiredo (2015) o limite aceitável para perdas na colheita da soja é de $60 \mathrm{~kg} \mathrm{ha}^{-1}$.

Sendo assim, este trabalho teve o objetivo de analisar o desempenho de uma colheitadeira de parcelas na cultura da soja com diferentes velocidades de deslocamento. 


\section{MATERIAIS E MÉTODOS}

O experimento foi conduzido na Estação Experimental do Centro Universitário UNISEP, localizado no município de Dois Vizinhos, Paraná, nas proximidades das coordenadas geodésicas: Latitude: $25^{\circ} 46^{\prime} 23^{\prime \prime} \mathrm{S}$ e Longitude: $53^{\circ} 3^{\prime} 10^{\prime \prime} \mathrm{W}$, com altitude média de 510 metros e clima Cfa, de acordo com classificação de Köeppen. O solo do local do experimento é classificado como Nitossolo Vermelho.

A condução da cultura da soja foi realizada em sistema plantio direto (trigo-soja), sendo utilizado o híbrido BASF BS 2606, semeado em 12 de dezembro de 2019, com espaçamento de $0,5 \mathrm{~m}$ entre linhas e 0,2 entre plantas, e a colheita foi realizada em 29 de março de 2020. No sulco de plantio, a adubação foi realizada com a formulação NPK 0223-23, com $300 \mathrm{~kg} \mathrm{ha}^{-1}$.

Para a colheita foi utilizada uma colhedora de parcelas da marca Foton Lovol, modelo DC-200 (Figura 1), de $75 \mathrm{cv}$ de potência, com uma plataforma de $2 \mathrm{~m}$ de largura e uma capacidade de alimentação de $2 \mathrm{~kg} \mathrm{~s}^{-1}$.

Figura 1 - Colhedora Foton Lovol modelo DC-200, utilizada no experimento.

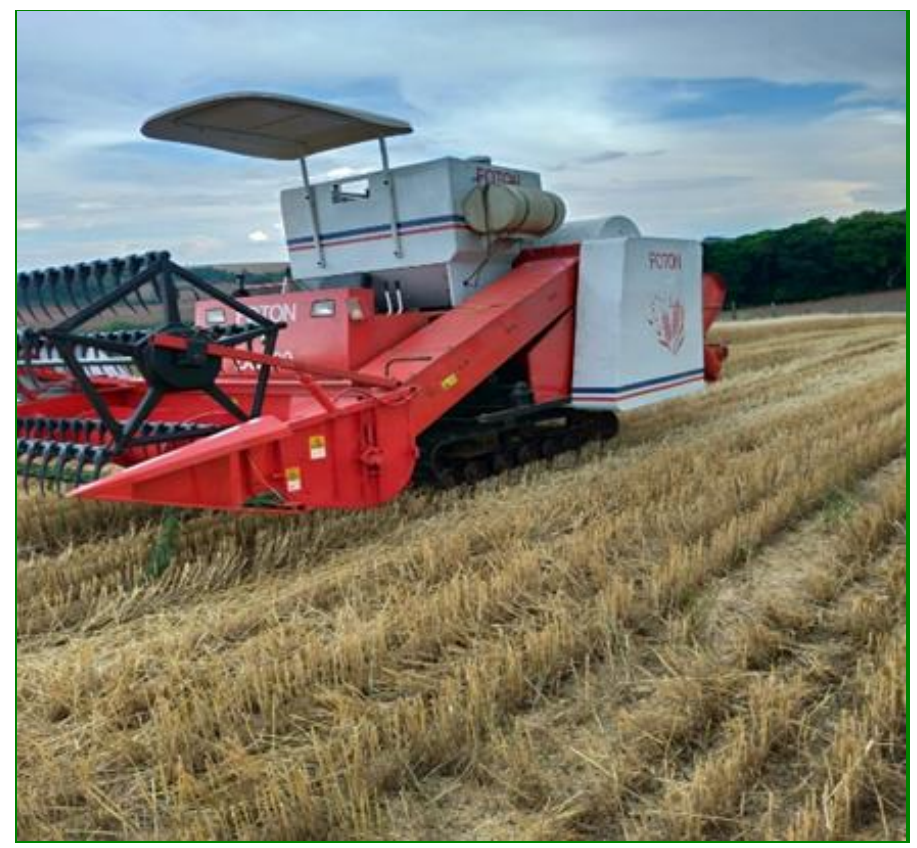

Fonte: Os autores, 2021.

O experimento foi instalado em delineamento em blocos casualizados, com quatro tratamentos e cinco repetições. A área da pesquisa foi demarcada com marcadores de 
campo dividindo-a em cinco blocos, e dentro de cada bloco foi demarcado quatro parcelas de 20 metros de comprimento e 2 metros de largura.

Cada tratamento representou uma velocidade de deslocamento da colheitadeira: 2, 4, 6 e $8 \mathrm{~km} \mathrm{~h}^{-1}$, onde foram avaliadas as seguintes variáveis: perdas na plataforma de trilha e corte, perdas totais número de vagens não recolhida pelo sistema, impureza e umidade.

Para estimativa das perdas, iniciou-se a colheita da soja, e após percorrer $50 \mathrm{~m}$ da parcela, retrocedeu-se com a colhedora uma distância igual ao seu comprimento, e coletouse todos os grãos, sendo classificados como perdas provocadas pelo sistema de trilha (kg $\left.\mathrm{ha}^{-1}\right)$, perdas na plataforma $\left(\mathrm{kg} \mathrm{ha}^{-1}\right)$ e perdas totais $\left(\mathrm{kg} \mathrm{ha}^{-1}\right)$ (BOCK et al., 2020). Além disso, foi realizada a contagem do número de vagens.

A determinação da impureza (\%) dos grãos foi realizada, conforme prescreve a norma de Qualidade para Classificação e comercialização da soja em Grão, utilizando-se 0,20 kg de grãos, como amostra. Para tanto, foi utilizada uma peneira classificatória com espessura de chapa de $810^{-4} \mathrm{~m}$, quantidade de furos $4000,10 \mathrm{~m}^{-2}$ e diâmetro dos furos de $310^{-3} \mathrm{~m}$. Considerou-se impureza todo material que vazou através da peneira, ou que nela ficou retido e que não seja soja, inclusive vagens não-debulhadas. Os resultados foram transformados em porcentagem.

O grau de umidade (\%) dos grãos foi determinado, utilizando-se aparelho da marca Motonko. Os grãos foram coletados, em quatro repetições no momento da descarga (HOLTZ \& REIS, 2013).

Os resultados obtidos foram submetidos à análise estatística, empregando-se os testes "F" e regressão polinomial.

\section{RESULTADOS E DISCUSSÃO}

As maiores perdas no sistema de trilha ocorreram com a velocidade de deslocamento de $2 \mathrm{~km} \mathrm{~h}^{-1}$, com 2,42 kg ha-1 e a menor perda com a velocidade de $8 \mathrm{~km} \mathrm{~h}^{-}$ 1 (0,88 kg ha-1) (Figura 2). De acordo com Bock et al. (2020), este resultado, se deve ao fato que quando a colhedora trabalha com uma taxa de alimentação baixa o produto fica exposto a uma maior corrente de vento, isso acaba contribuindo com perdas de grãos no sistema de trilha e limpeza. Para Paixão et al. (2017), esse uso de maiores velocidades na colheita da soja já demonstrou menor valor de dano mecânico e maior vigor em sementes de soja. 
Figura 2 - Perdas na plataforma de trilha $\left(\mathrm{kg} \mathrm{ha}^{-1}\right)$ em colhedora de parcelas em função de diferentes velocidades de deslocamento.

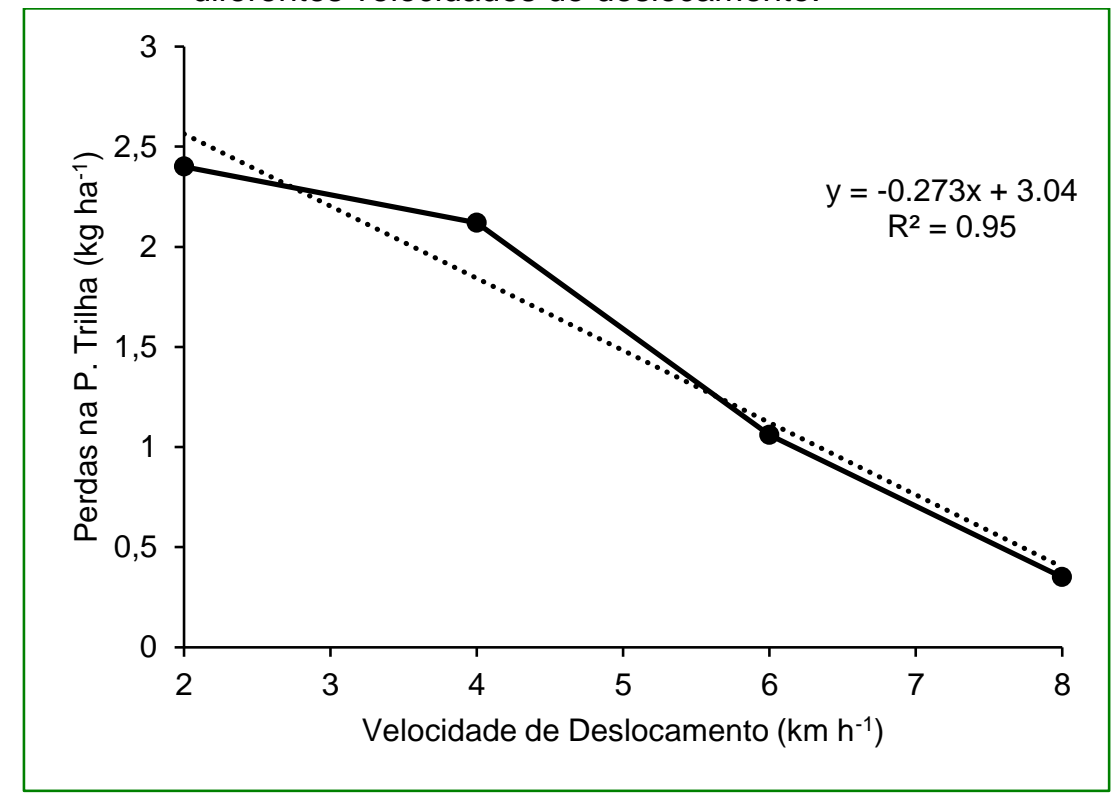

Fonte: Os autores, 2021.

Fernandes et al. (2018) relatam que as perdas no sistema de trilha, separação e limpeza ocorrem por quebras e danos e causados aos grãos nesta operação ou então por grãos e vagens que são jogados fora no sistema de ventilação da colhedora.

Verifica-se a diminuição das perdas na plataforma com o aumento da velocidade de deslocamento, sendo que a velocidade de $8 \mathrm{~km} \mathrm{~h}^{-1}$, apresentou uma perda de 0,88 $\mathrm{kg} \mathrm{ha}^{-1}$ e a velocidade de deslocamento de $2 \mathrm{~km} \mathrm{~h}^{-1}$ apresentou uma perda de 2,4 $\mathrm{kg} \mathrm{ha}^{-1}$ (Figura 3). Os resultados obtidos discordam de Machado et al. (2012), que relatam que o aumento de velocidade de deslocamento provoca um aumento de quantidade de plantas tombadas e não colhidas, o que ocasiona perdas mais elevadas e de Mesquita et al. (2006), que afirmam que menores perdas na colheita ocorrem para velocidades próximas à faixa de 4,5 a $5,5 \mathrm{~km} \mathrm{~h}^{-1}$. 
Figura 3 - Perdas na plataforma de corte $\left(\mathrm{kg} \mathrm{ha}^{-1}\right)$ em colhedora de parcelas em função de diferentes velocidades de deslocamento.

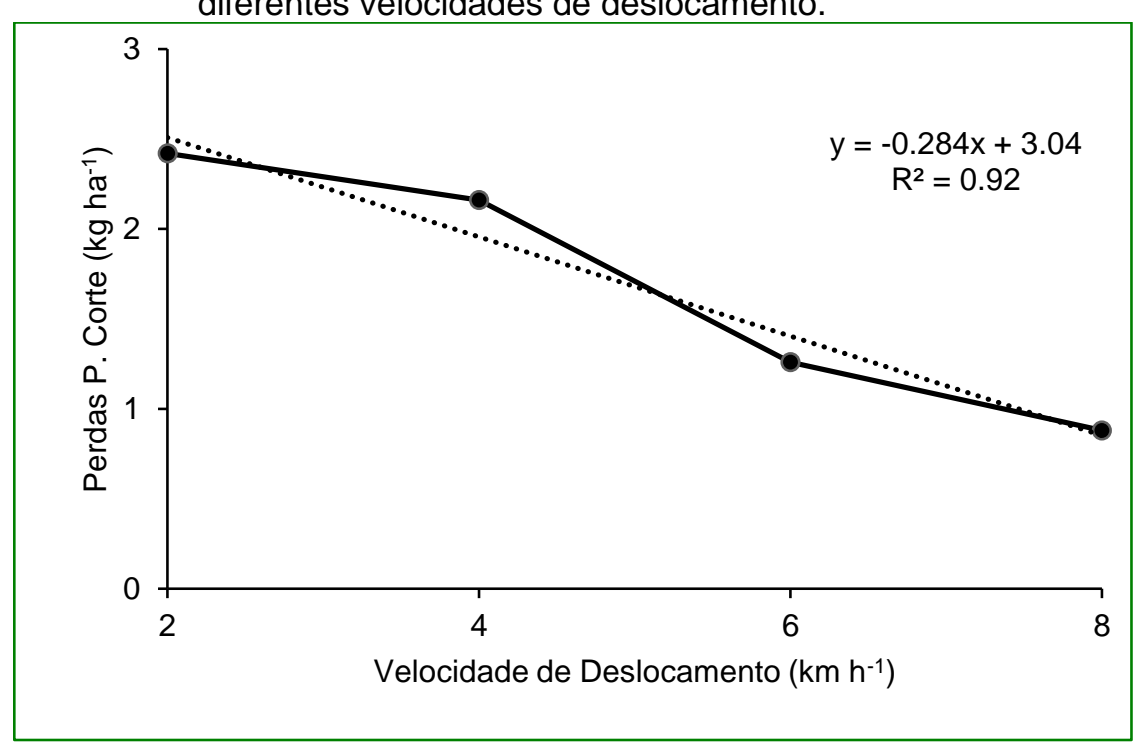

Fonte: Os autores, 2021.

Para Pinheiro Neto \& Troli (2003), as perdas na plataforma ocorrem devido aos grãos que são debulhados no molinete, pelas plantas cortadas e que são jogadas ao solo, e pelas vagens que não atingem a elevada altura da barra de corte, e portanto, não chegam aos mecanismos internos da colhedora.

As perdas totais são resultado do somatório das perdas na plataforma e do sistema de trilha da colhedora (HOLTZ et al., 2019). Analisando-se as perdas totais da colhedoracom as diferentes velocidades de deslocamento (Figura 4), percebe-se que todas velocidades utilizadas as perdas totais foram bem inferiores aos limites para colhedoras convencionais que é de $60 \mathrm{~kg} \mathrm{ha}^{-1}$ (Zandonadi, Ruffato e Figueiredo, 2015). 
Figura 4 - Perdas totais $\left(\mathrm{kg} \mathrm{ha}^{-1}\right)$ em colhedora de parcelas em função de diferentes velocidades de deslocamento.

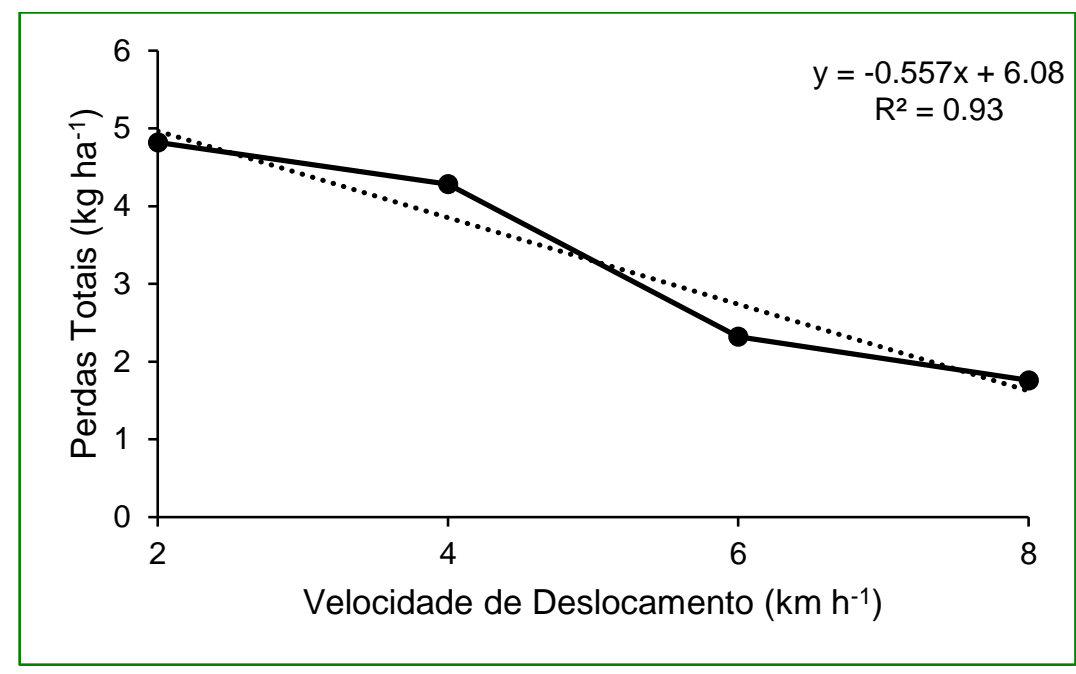

Fonte: Os autores, 2021.

Ocorreu semelhança entre as perdas totais e as perdas na plataforma e no sistema de trilha, com diminuição das perdas totais com o aumento da velocidade de deslocamento. No entanto, Lima et al. (2017), concluíram que aumentando a velocidade de deslocamento da colhedora de 5 para $7 \mathrm{~km} \mathrm{~h}^{-1}$ resulta em maiores perdas médias na colheita mecanizada da soja.

Campos et al. (2005) ao avaliarem a influência da velocidade operacional em colhedoras na cultura da soja, não observaram perdas quantitativas de grãos, por deficiência na altura de corte, sistema de limpeza e perdas totais.

Os resultados obtidos do número de vagens em função das diferentes velocidades de deslocamento (Figura 5) diferem de Camolese, Baio e Alves (2015), que relatam que velocidades elevadas proporcionam maior impacto, podendo levar a maior abertura de vagens, e também exigem uma maior velocidade angular do molinete, podendo acarretar em debulha de vagens. 
Figura 5 - Número de vagens de soja no solo em função de diferentes velocidades de deslocamento.

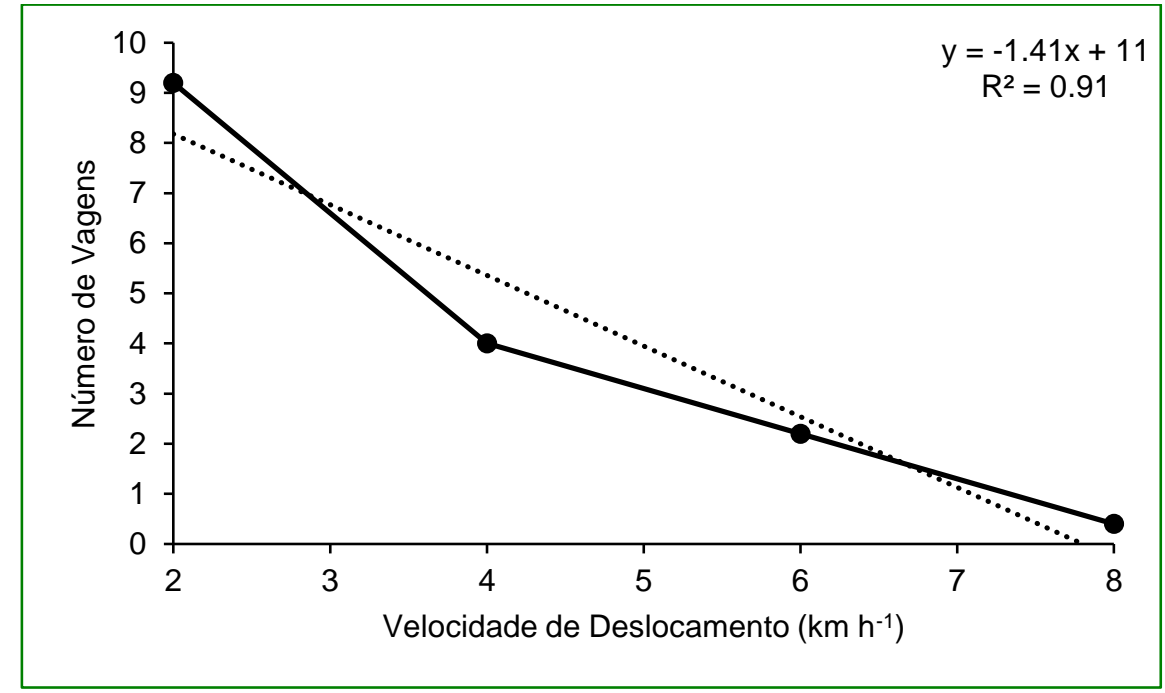

Fonte: Os autores, 2021.

Analisando a impureza na colheita da soja com diferentes de deslocamento. Podese observar que as o menor teor de impureza da soja foi obtido com as maiores velocidades de deslocamento. Os resultados obtidos discordam de Vieira et al. (2006), que concluíram que a velocidade de deslocamento não influencia nos índices de impurezas na colheita da soja (Figura 6).

Figura 6 - Impureza (\%) de soja em função de diferentes velocidades de deslocamento.

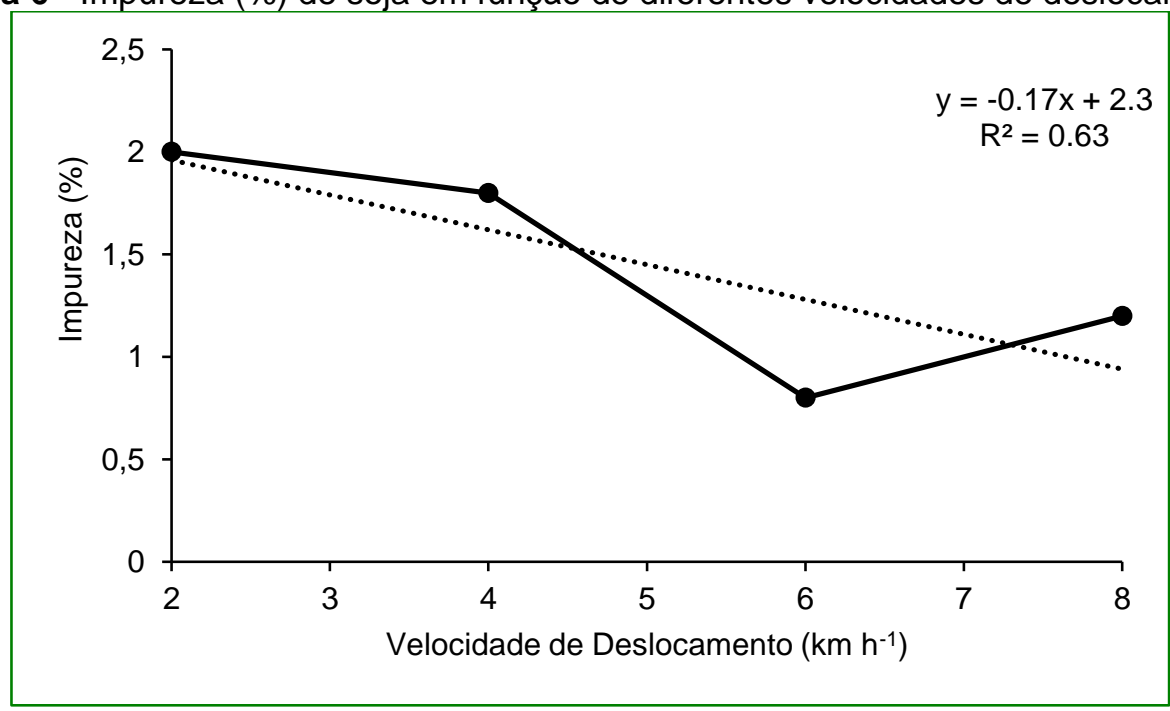

Fonte: Os autores, 2021. 
Os resultados da umidade, indicam que as velocidades de 4, 6 e $8 \mathrm{~km} \mathrm{~h}^{-1}$ (Figura 7), estão dentro da faixa ideal que deve ser entre 12 e 14\%, que permite a manutenção da regulagem dos mecanismos internos da colhedora (rotação do cilindro de trilha, abertura entre cilindro e côncavo, etc.), dentro de certos limites, reduzindo-se assim perdas e danos mecânicos (COMPAGNON et al., 2012).

Figura 7 - Umidade (\%) de soja nas diferentes velocidades de deslocamento em colheitadeira de parcelas.

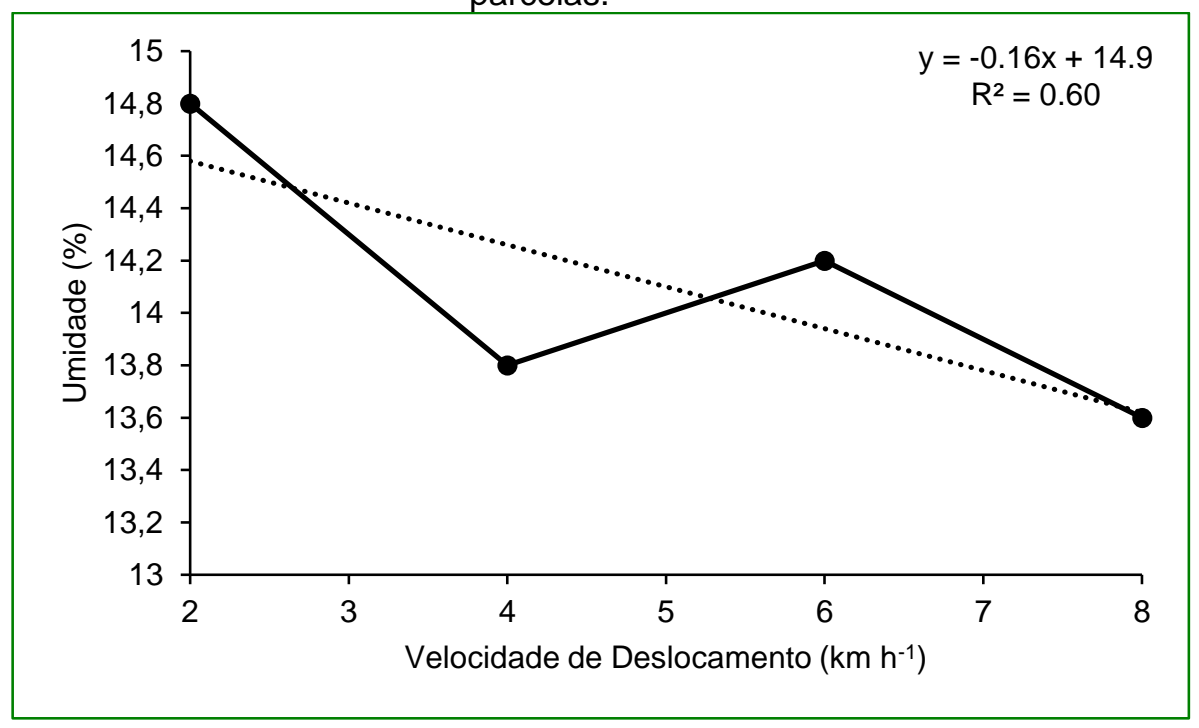

Fonte: Os autores, 2021.

Apesar dos valores de umidade estarem dentro dos limites, o fato da velocidade de $2 \mathrm{~km} \mathrm{~h}^{-1}$ obter a maior umidade, e as maiores perdas podem estar interligados. Para Schakoski et al. (2011), a avaliação da umidade nas perdas da colheita mecanizada é de extrema importância, pois é o fator ambiental que mais interfere nas perdas.

\section{CONCLUSÕES}

A umidade dos grãos não influenciou nas perdas da plataforma, de trilha e totais.

A velocidade de $2 \mathrm{~km} \mathrm{~h}^{-1}$, proporcionou as menores perdas, enquanto que a velocidade de $8 \mathrm{~km} \mathrm{~h}^{-1}$ obteve as maiores perdas.

O aumento na velocidade de colheita da soja diminuiu as perdas na colhedora de parcelas. 


\section{REFERÊNCIAS}

BOCK, R. et al. Perdas na colheita mecanizada de soja em função da velocidade de deslocamento e índice de molinete. Brazilian Journal of Development, São José dos Pinhais, v. 6(6): 34707-34724, 2020. DOI: 10.34117/bjdv6n6-131.

CAMOLESE, H. S.; BAIO, F. H. R.; ALVES, C. Z. Perdas quantitativas e qualitativas de colhedoras com trilha radial e axial em função da umidade do grão. Revista Brasileira de Engenharia de Biossistemas, Tupã, v. 9(1): 21-29, 2015. DOI:

10.18011/bioeng2015v9n1p21-29.

CAMPOS, M. A. O. et al. Perdas na colheita mecanizada da soja no estado de Minas Gerais. Engenharia Agrícola, Jaboticabal, v. 25(1): 207-213, 2005. DOI: 10.1590/S010069162005000100023.

COMPAGNON, A. M. et al. Comparação entre métodos de perdas na colheita mecanizada da soja. Scientia Agropecuaria, Trujillo, v.3: 215-223, 2012. DOI: 10.72268/sci.agropecu.2012.03.03.

COMPANHIA NACIONAL DE ABASTECIMENTO - CONAB. Acompanhamento da safra brasileira. Disponível em: < https://www.conab.gov.br/info-agro/safras> Acesso em: 26/02/2021.

FERNANDES, C. H. S. F.; TEJO, D. P.; BURATTO, J. S. Perdas na colheita da soja. Revista Científica Eletrônica de Agronomia da FAEF, Garça, v. 33(1): 28-44, 2018.

FREITAS, R. E.; MENDONÇA, M. A. A. Expansão agrícola no Brasil e a participação da soja: 20 anos. Revista de Economia e Sociologia Rural, Brasília, v. 54(3): 497-516, 2016. DOI: 10.1590/1234-56781806-94790540306.

GURGACZ, F. et al. Avaliação de perdas e quebra de grãos em função da velocidade de colheita mecânica da cultura da soja. Revista Técnico-Científica do CREA-PR, Curitiba, Edição Especial, 2019.

HOLTZ, V.; REIS, E. F. Perdas na colheita mecanizada de soja: uma análise quantitativa e qualitativa. Revista Ceres, Viçosa, v.60(3): 347-353, 2013. DOI: 10.590/S0034737X2013000300007.

HOLTZ, V. et al. Perdas na colheita mecanizada de soja utilizando diferentes mecanismos na plataforma de corte. Pubvet, Maringá, v. 13(2): 1-6, 2019.

LIMA, F. B. F.; SILVA, M. A. F.; SILVA, R. P. Quality of mechanical soybean harvesting at two travel speeds. Engenharia Agrícola, Jaboticabal, v. 37(6): 1171-1182, 2017. DOI: 10.1590/1809-4430-Eng.Agric.v37n6p1171-1182/2017.

MACHADO, T. A. et al. Perdas na plataforma de corte de uma colhedora combinada de grãos na colheita de soja. Engenharia na Agricultura, Viçosa, v. 20(6): 537-543, 2012. DOI: 10.13083/reveng.v20i6.378. 
MARTIN, T. N. et al. Metodologia experimental para rendimento de grãos de soja em condições de restrição de espaço. Bragantia, Campinas, v. 66(3): 521-526, 2007. DOI: 10.1590/S0006-87052007000300020.

MESQUITA, C. M.; HANNA, M. A.; COSTA, N. P. Crop and harvesting operation characteristics affecting field losses and physical qualities of soybeans - Part 1. Applied Engineering in Agriculture, St. Joseph, v. 22: 325-333, 2006. DOI:

10.13031/2013.20449.

PAIXÃO, C. S. S. et al. Physical and physiological quality of soybean seeds at three speeds of the harvester. Revista Brasileira de Engenharia Agrícola e Ambiental, Campina Grande, v. 21: 214-218, 2017. DOI: 10.1590/1807-1929/agriambi.v21n3p214218.

PINHEIRO NETO, R.; TROLI, W. Perdas na colheita mecanizada da soja (Glycine Max (L.) Merril), no município de Maringá, Estado do Paraná. Acta Scientiarum Agronomy, Maringá, v.25(2): 393-398, 2003. DOI: 10.4025/actasciagron.v25i2.1995.

SCHNAKOSKI, R.; RIGHI, E. Z.; WERNER, V. Perdas na colheita mecanizada da soja (Glycine max) no município de Maripá - PR. Revista Brasileira de Engenharia Agrícola e Ambiental, Campina Grande, v. 15(11): 1206-1211, 2011. DOI: 10.1590/S1141543662011001100015.

VIEIRA, B. G. T. L.; SILVA, R. P.; VIEIRA, R. D. Qualidade física e fisiológica de semente de soja colhida com sistema de trilha axial sob diferentes velocidades de operação e rotações do cilindro trilhador. Engenharia Agrícola, Jaboticabal, v. 26(2): 478-482, 2006. DOI: 10.1590/S0100-69162006000200016.

ZANDONADI, R. S.; RUFFATO, S.; FIGUEIREDO, Z. N. Perdas na colheita mecanizada de soja na região médio-norte de Mato Grosso: Safra 2013/2014. Nativa, Sinop, v. 3(1): 64-66, 2015. DOI: 10.14583/2318-7670.v03n01a11. 


\begin{abstract}
The mechanized harvesting of soybean is fundamental tool in the production process of this crop, and if not performed properly, it can result in severe mechanical damage to the grains, causing significant losses at harvest. This concern with harvest must also be taken into account in experimental fields, when plot harvesters are used. The aim of the present study was to assess losses occurring in mechanized harvesting with plot harvester with diffent displacement speed. Combine header, thresing and total losses were assessed. In addition, the impurity number of pods and the moisture content of the grains were evaluated, with displacement speeds of: 2, 4, 6 and $8 \mathrm{~km} \mathrm{~h}^{-1}$. The increase of displacement speed provided less losses in mechanized harvesting of soybean. The number of pods, such as impurities and humidity, were also influenced by the increase in displacement speed.
\end{abstract}

Keywords: Glycine max (L.) Merrill. Mechanizated harvest. Harvesting losses.

\title{
RESUMEN
}

La recolección mecanizada de soja es fundamental en el proceso productivo de este cultivo y, si no realiza adecuadamente, puede resultar en severos daños mecánicos a los granos, provocando importantes pérdidas en la cosecha. Esta preocupación por la cosecha también debe tenerse en cuenta en los campos experimentales, cuando se utilizan cosechadoras de parcelas. El objetivo de este trabajo fue evaluar las pérdidas ocurridas en la recolección mecanizada con una cosechadora de parcelas con diferentes velocidades de desplazamiento. Se evaluaron las pérdidas totales en la plataforma, en el camino. Además, se evaluó impureza, número de vainas y humedad del grano, con velocidad de desplazamiento de: 2, 4, 6 y $8 \mathrm{~km} \mathrm{~h}^{-1}$. El aumento de la velocidad de desplazamiento proporcionó menos pérdidas en la recolección mecanizada. El número de vainas, impurezas y humedad también se vieron influenciados por el aumento de la velocidad de desplazamiento.

Palabras-clave: Glycine max (L.) Merrill. Cosecha mecanizada. Pérdidas de cosecha. 


\section{LICENÇA DE USO}

Este é um artigo publicado em acesso aberto (Open Access) sob a licença Creative Commons Atribuição 4.0 Internacional (CC BY 4.0), que permite uso, distribuição e reprodução em qualquer meio, desde que o trabalho original seja corretamente citado. Mais informações em: http://creativecommons.org/licenses/by/4.0

\section{CONFLITO DE INTERESSES}

Os autores declaram que não há conflito de interesses neste trabalho.

\section{CONTRIBUIÇÕES AUTORAIS}

Autor 1: Responsável pela execução e coleta de dados e redação do trabalho.

Autor 2: Responsável pela co-orientação e revisão do artigo.

Autor 3: Responsável pela orientação e planejamento do trabalho.

Autor 4: Auxílio na revisão do trabalho e sugestões na discussão.

Autor 5: Responsável pelo planejamento experimental e auxílio na coleta de dados.

Autor 6: Auxílio na coleta de dados do trabalho.

Autor 7: Auxílio na revisão do trabalho, sugestões e elaboração deste texto.

Autor 8: Auxílio na revisão do trabalho, sugestões e elaboração deste texto.

\section{FINANCIAMENTO}

O presente trabalho não contou com apoio financeiro.

\section{COMO REFERENCIAR}

DANIELI, Matheus; LOPES, Allan Remor; DOTT, Marcelo; XAVIER, Elouize; MACHADO, André Bressiani; SCHIAVINI, Vinicius Eduardo; GIAROLA, Camila Moreno; PIROLA, Kelli. Desempenho de colhedora de parcelas na soja com diferentes velocidades de deslocamento. Revista Brasileira de Engenharia de Biossistemas (Tupã), v. 15, n. 2, p. 207-219, 2021. DOI: http://dx.doi.org/10.18011/bioeng2021v15n2p207-219.

\section{RESPONSABILIBADE EDITORIAL}

Prof. Dr. Fernando Ferrari Putti ${ }^{1}$, Prof. Dr. Paulo Sérgio Barbosa dos Santos ${ }^{1}$, Prof. Dr. Eduardo Festozo Vicente ${ }^{1}$ e Prof. Dr. Diogo de Lucca Sartori ${ }^{1}$

1 Universidade Estadual Paulista "Júlio de Mesquita Filho", FCE - Faculdade de Ciências e Engenharia, Tupã, SP, Brasil. 